\title{
Association between C1019T polymorphism of the connexin37 gene and coronary heart disease in patients with in-stent restenosis
}

\author{
SU-XIA GUO, ZHEN-YU YANG, RU-XING WANG, YING YANG, HUA-MING CAO and TAO ZHANG \\ Department of Cardiology, The Affiliated People's Hospital of Nanjing Medical University in Wuxi \\ and People's Hospital of Wuxi City, Jiangsu, Wuxi 214023, P.R. China
}

Received October 16, 2012; Accepted November 19, 2012

DOI: $10.3892 /$ etm.2012.852

\begin{abstract}
Studies have shown that a C1019T polymorphism of the gene encoding the gap junction protein connexin 37 is associated with coronary artery disease (CAD). The aim of the present study was to explore the association between the C1019T polymorphism in the connexin37 gene and CAD patients with in-stent restenosis (ISR). A total of 532 patients who had undergone coronary stenting and coronary angiography at least three months after the procedure were divided according to a clinical diagnosis standard into two groups which were ISR $(n=67)$ and no in-stent restenosis (NISR; n=465) groups. A further 501 healthy individuals were controls. The subjects were genotyped by DNA sequencing. The results demonstrated the following: i) connexin37 gene 1019 sites in the population were distributed by polymorphism into three genetic types (CC, TC and TT types). The distribution frequency of the healthy control, ISR and NISR groups conformed to the Hardy-Weinberg genetic balance rule; ii) in comparison with the healthy controls, the frequency of the connexin37 $\mathrm{C}$ allele was higher in the CAD patients (57.05\% vs. 41.32\%; OR, 1.89; 95\% CI, 1.58-2.25; $\mathrm{P}<0.01$ ). The frequency of the $\mathrm{C}$ carriers (CC+TC) was $65.47 \%$ in the healthy controls, vs. $79.32 \%$ in CAD patients $(\mathrm{P}<0.01)$. The $\mathrm{CAD}$ risk was significantly increased in the carriers of the $\mathrm{C}$ allele (CC+TC) compared with TT homozygotes (OR, 2.03; 95\% CI, 1.53-2.80; $\mathrm{P}<0.01)$. Stratified analysis demonstrated that a significant difference existed in the frequency of $\mathrm{C}$ carriers between the male CAD patients and healthy controls (79.63\% vs. $72.45 \%$; OR, 1.48 ; $95 \%$ CI, $1.06-2.09, \mathrm{P}=0.02)$, as well as in the female CAD patients $(78.00 \%$ vs. $51.50 \%$; OR, 3.34; $95 \%$ CI, 1.90-5.86; $\mathrm{P}<0.01)$. In the female and male CAD patients, the frequency of the connexin $37 \mathrm{C}$ allele was higher
\end{abstract}

Correspondence to: Dr Su-Xia Guo or Dr Zhen-Yu Yang, Department of Cardiology, The Affiliated People's Hospital of Nanjing Medical University in Wuxi and People's Hospital of Wuxi City, Wuxi, 299 Qingyang Road, Jiangsu 214023, P.R. China

E-mail:suxiaguocn@163.com

E-mail: zhenyuyang3746@126.com

Key words: coronary heart disease, in-stent restenosis, connexin37, gene polymorphism than in the healthy controls (male: $\chi^{2}=12.67, \mathrm{P}<0.01$; female: $\left.\chi^{2}=50.20, \mathrm{P}<0.01\right)$; iii) compared with the NISR group, the frequencies of the connexin $37 \mathrm{C}$ allele and $\mathrm{C}$ carriers (CC+TC) were significantly higher in the ISR group (frequency of $\mathrm{C}$ allele: $72.39 \%$ vs. $54.84 \%$; $\mathrm{P}<0.01$; frequency of $\mathrm{C}$ carriers: $89.55 \%$ vs. $77.85 \%$; $\mathrm{P}=0.03)$. Compared with TT homozygotes, the restenosis risk was significantly increased in the carriers of the C allele (CC+TC; OR, 2.44; 95\% CI, 1.08-5.50). Subsequent stratified analysis revealed that the frequency of the $\mathrm{C}$ allele was significantly higher in the male ISR group than in the male NISR group (78.57\% vs. 52.66\%; OR, 3.30; 95\% CI, 2.05-5.29; $\mathrm{P}<0.01)$. The restenosis risk was $\sim$ four-fold higher in the $\mathrm{C}$ carriers $(\mathrm{CC}+\mathrm{TC})$ than in the TT homozygotes (OR, 3.74; $95 \% \mathrm{CI}, 1.32-10.64)$. However in the female population, there was no difference in the ISR risk between the carriers of the $\mathrm{C}$ allele $(\mathrm{CC}+\mathrm{TC})$ and the TT homozygotes $(\mathrm{P}=0.70)$. In summary, the $\mathrm{C}$ allele of the connexin 37 gene is not only is associated with the susceptibility to CAD, but also associated with restenosis following coronary stenting in the population studied herein, particularly the male population.

\section{Introduction}

Percutaneous coronary intervention (PCI) is well-established treatment strategy for coronary artery disease (CAD), particularly following the introduction of drug-eluting stents $(1,2)$. Despite technological and pharmacological advances, the main limitation of PCI is in-stent restenosis (ISR), which is due to neointimal hyperplasia following the arterial wall injury induced by balloon inflation and stent placement $(3,4)$. Smooth muscle cell (SMC) migration and proliferation is considered be key to intima repair. In this reparative process, genetic factors are involved as well as conventional clinical and procedural parameters $(5,6)$. Consequently, additional genetic tests to identify patients at a high risk of restenosis may lead to improved risk stratification and eventually individual patient-tailored therapy.

Connexins are members of a family of proteins encoded by at least 20 different mammalian genes expressed in a wide variety of tissues (7-9). They form transmembrane channels called gap junctions which connect neighboring cells and allow the passive diffusion of small molecules (10). Of the connexin family, connexin 37 is the most highly expressed in the vascular endothelium and is involved in the growth and regeneration 
of endothelial cells after injury and ageing, suggesting that changes in connexin 37 are associated with diseases following intima injury, including CAD and ISR (11-13).

Boerma et al identified a link between a single nucleotide polymorphism (SNP) in the human connexin37 gene and the thickening of the carotid in a Swedish male population (14), with the $\mathrm{C}$ allele being over-represented in individuals with atherosclerotic plaques. The $\mathrm{C}$ allele of this SNP has also been associated with CAD in Taiwan, northern China and Switzerland (15-17). Subsequently in two studies performed in Japanese and Caucasian populations, the T SNP has been shown to be a risk factor for acute myocardial infarction (AMI), particularly in high-risk male individuals $(18,19)$.

Although it is not clear which allele is the more closely associated, the majority of gene polymorphism-association studies have detected that the C1019T SNP in the human connexin 37 gene is associated with CAD and myocardial infarction (MI) in various populations. However, whether such a polymorphism may be used as a prognostic marker of ISR following percutaneous coronary intervention, is not known. The present study was designed to investigate whether the connexin37 C1019T polymorphism is associated with restenosis following coronary stenting in the Han population of Wuxi City in China.

\section{Materials and methods}

Population. This was a single-center, prospective observational study. A total of 532 Han Chinese patients who had undergone successful coronary stenting at the Cardiac Unit of Nanjing Medical University Hospital in Wuxi between 2009 and 2011 and returned for follow-up coronary angiography at least three months later (median, eight months) were selected. In particular, if clinical symptoms appeared (such as chest pain and abnormality in electrocardiograms or cardiac enzymes), coronary angiography was performed at any time. All patients regularly received anti-platelet drugs (aspirin $100 \mathrm{mg} /$ day, clopidogrel $75 \mathrm{mg} /$ day), statins (types and doses determined by doctors) and other necessary drugs, such as angiotensin-converting enzyme inhibitor, $\beta$-blockers and nitrates, after the procedure. A further 501 healthy individuals from the medical examination center of the same hospital were the controls. No patients or controls were blood relatives. All participants gave written consent and the ethics committee of People's Hospital of Wuxi City approved the study.

Collection of clinical and epidemiological data. Questionnaires were filled out to record basic information for each case (such as age, gender and nationality), risk factors for restenosis (hypertension, diabetes mellitus, hyperlipidemia and smoking/drinking history) and family history of cerebrocardiac vessel disease. Information concerning disease onset, date of patient examinations during hospitalization and procedure-associated information were also collected.

Quantitative coronary analysis (QCA). QCA was performed as described previously on images obtained before and immediately after stent placement and at follow-up using a computerized quantitative analysis system. The angiography was performed with at least two projections following an intracoronary injection of isosorbide dinitrate $(0.2 \mathrm{mg})$. The tip of a $6 \mathrm{~F}$ or $7 \mathrm{~F}$ catheter filled with contrast medium was used for calibration. Restenosis was defined as a $\geq 50 \%$ diameter reduction in the dilated segment.

Genotyping. DNA was purified from samples of whole white blood cells, which had been stored frozen at $-20^{\circ} \mathrm{C}$. Purification was performed using a DNA Purification kit (Promega Inc., Madison, WI, USA) according to the manufacturer's instructions. The polymerase chain reaction (PCR) was conducted with the upstream primer, 5'-CCTCCTCAGACCCTTACACGG-3' and downstream primer, 5'-CATCCCAGGCAGCCAGACT-3' (designed and produced by Ying-Jun Biological Company, Shanghai, China). A $20-\mu 1$ reaction volume was used for PCR containing $10 \mu 12 \mathrm{X}$ mix (including $\mathrm{Mg}^{+}$, dNTPs and Taq DNA polymerase), $1.0 \mu 1$ upstream primer (10 pmol), $1.0 \mu 1$ downstream primer (10 pmol), $2 \mu \mathrm{l}$ genomic DNA template (up

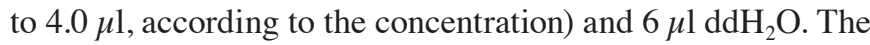
reaction began with denaturation at $94^{\circ} \mathrm{C}$ for $5 \mathrm{~min}$, followed by 35 cycles of denaturation at $95^{\circ} \mathrm{C}(30 \mathrm{sec})$, annealing at $60^{\circ} \mathrm{C}$ $(30 \mathrm{sec})$, extension at $72^{\circ} \mathrm{C}(30 \mathrm{sec})$ and a final extension at $72^{\circ} \mathrm{C}(7 \mathrm{~min})$. Genotype analysis was performed using DNA sequencing, which was completed by Ying-Jun Biological Company.

Statistical analysis. Allele frequencies were calculated by allele counting. Analyses for possible deviations of the genotype distribution from that expected for a population in Hardy-Weinberg equilibrium were performed with the $\chi^{2}$ test. Data are presented as the mean \pm SD or number (proportion, \%). Continuous variables with a Gaussian distribution, as determined by the Shapiro-Wilk test, were compared by one-way analysis of variance (ANOVA) or t-tests. Categorical values were compared by the $\chi^{2}$ test. Continuous variables with a non-Gaussian distribution were compared by the Mann-Whitney U test. Analyses were performed using the SPSS statistical software (Version 13.0, SPSS Inc, Chicago, IL, USA). $\mathrm{P}<0.05$ was considered to indicate a statistically significant difference.

\section{Results}

Baseline characteristics. A total of 501 healthy individuals formed the control group and 532 patients were enrolled, 67 of whom developed ISR. The distribution of clinical and procedure-associated factors, including age, gender, body mass index (BMI) and hypertension, were not observed to be significantly different between the ISR and no in-stent restenosis (NISR) groups. Stent length, stent diameter and release pressure exhibited no differences between the ISR and NISR groups (Table I).

Connexin 37 C1019T genotyping and association analysis. The C1019T polymorphism of the connexin37 gene was detected in the whole population (Fig. 1). The genotype frequencies of CC, TC and TT in the connexin37 C1019T polymorphism were $17.16,48.30$ and $34.53 \%$ in the healthy control group; $55.22,34.33$ and $10.45 \%$ in ISR group; and $31.83,46.02$ and $22.15 \%$ in the NISR groups, respectively. They all obeyed the Hardy-Weinberg law. 
Table I. Comparison of the clinical data of patients among the three groups.

\begin{tabular}{|c|c|c|c|}
\hline Factor & Control group $(n=501)$ & NISR group $(n=465)$ & ISR group $(n=67)$ \\
\hline Age (years) & $62.07 \pm 8.51$ & $62.64 \pm 12.00$ & $59.18 \pm 8.48$ \\
\hline Gender (male/female) & $334 / 167$ & $376 / 89$ & $56 / 11^{\mathrm{ab}}$ \\
\hline BMI & $24.48 \pm 3.25$ & $24.53 \pm 3.36$ & $24.49 \pm 3.41$ \\
\hline Systolic blood pressure (mmHg) & $130 \pm 21$ & $132 \pm 18$ & $138 \pm 25$ \\
\hline Diastolic blood pressure ( $\mathrm{mmHg}$ ) & $84 \pm 16$ & $90 \pm 20$ & $92 \pm 24$ \\
\hline Fasting blood sugar (mmol/l) & $5.26 \pm 0.98$ & $5.73 \pm 1.00$ & $5.72 \pm 0.82$ \\
\hline Creatinine $(\mathrm{mg} / \mathrm{dl})$ & $85.11 \pm 21.63$ & $87.33 \pm 15.07$ & $81.57 \pm 16.93$ \\
\hline \multicolumn{4}{|l|}{ History } \\
\hline Smoking (yes/no) & $378 / 123$ & $417 / 48$ & $58 / 9^{\mathrm{ab}}$ \\
\hline Drinking (yes/no) & $346 / 155$ & $356 / 109$ & $49 / 18^{\mathrm{ab}}$ \\
\hline \multicolumn{4}{|l|}{ Stent } \\
\hline Diameter (mm) & - & $2.98 \pm 0.67$ & $2.79 \pm 0.87^{b}$ \\
\hline Length (mm) & - & $23.46 \pm 8.59$ & $24.16 \pm 9.23^{\mathrm{b}}$ \\
\hline Stent release pressure (atm) & - & $14.23 \pm 4.68$ & $15.11 \pm 3.42^{b}$ \\
\hline Drug & - & & \\
\hline Aspirin (yes/no) & - & $465 / 2$ & $67 / 0$ \\
\hline Clopidogrel (yes/no) & - & $465 / 0$ & $67 / 0$ \\
\hline$\beta$-blockers (yes/no) & - & $457 / 8$ & $65 / 2$ \\
\hline ACEI/ARB(yes/no) & - & $445 / 20$ & $64 / 3$ \\
\hline Statins (yes/no) & - & $463 / 2$ & $66 / 1$ \\
\hline
\end{tabular}

Data expressed as mean $\pm \mathrm{SD}$. ${ }^{\mathrm{a}} \mathrm{P}<005$ compared among the three groups. ${ }^{\mathrm{b}} \mathrm{P}<0.05$ compared with the NISR group. ACEI, angiotensin-converting enzyme inhibitor; ARB, angiotensin receptor blocker; BMI, body mass index; ISR, in-stent restenosis; NISR, no in-stent restenosis.

A

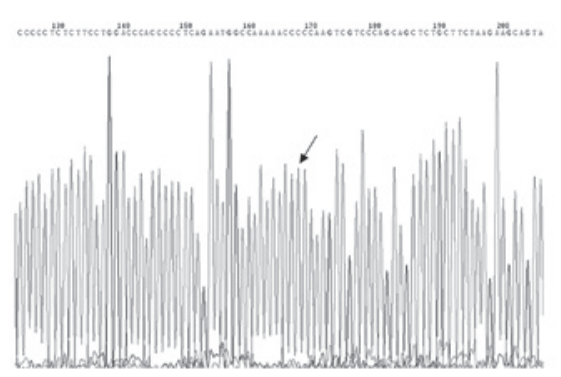

C
B

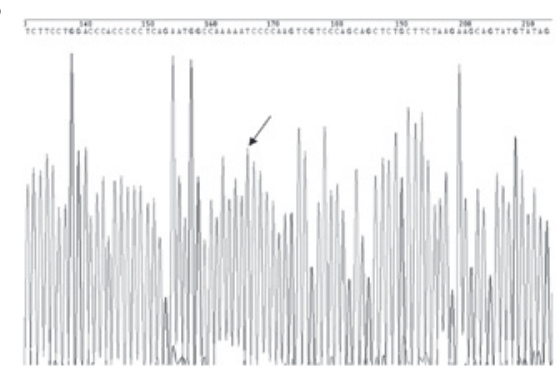

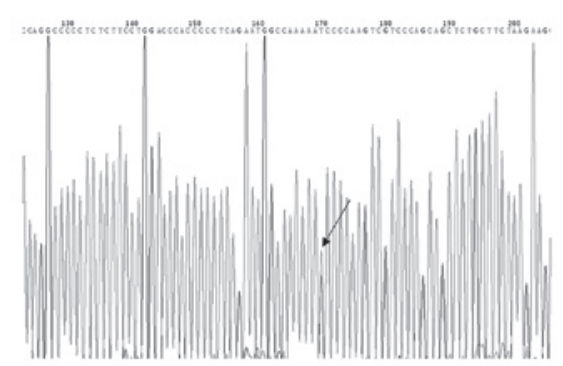

Figure 1. Gene sequencing diagram. (A) CC type. (B) TT type. (C) TC type.

Compared with the healthy controls, the frequency of the connexin37 $\mathrm{C}$ allele was higher in the CAD patients (57.05\% vs. 41.32\%; OR, 1.89; 95\% CI, 1.58-2.25; $\mathrm{P}<0.01)$. The frequency of $\mathrm{C}$ carriers (CC+TC) was $79.32 \%$ in the CAD patients and $65.47 \%$ in the healthy controls $(\mathrm{P}<0.01)$. The CAD risk was significantly increased in the carriers of the $\mathrm{C}$ allele
(CC+TC) compared with TT homozygotes (OR, 2.03; 95\% CI, 1.53-2.80). Subsequent stratified analysis demonstrated that a significant difference existed in the frequency of $\mathrm{C}$ carriers between the male CAD patients and healthy controls $(79.63 \%$ vs. $72.45 \%$; OR, 1.48 ; $95 \% \mathrm{CI}=1.06-2.09, \mathrm{P}=0.02)$, as well as in the female CAD patients $(78.00 \%$ vs. $51.50 \%$; OR, 3.34; 
Table II. Analysis of gene polymorphism test results in the CAD and control groups (\%).

\begin{tabular}{|c|c|c|c|c|c|c|}
\hline \multirow[b]{2}{*}{ Group } & \multicolumn{4}{|c|}{ Genotype } & \multicolumn{2}{|c|}{ Allele } \\
\hline & $\mathrm{CC}$ & $\mathrm{CT}$ & $\mathrm{TT}$ & $\mathrm{CC}+\mathrm{TC}$ & $\mathrm{C}$ & $\mathrm{T}$ \\
\hline CAD group $(n=532)$ & $185(34.77)$ & $237(44.55)$ & $110(20.68)$ & $422(79.32)$ & $607(57.05)$ & $457(42.95)$ \\
\hline Control group $(n=501)$ & $86(17.16)$ & $242(48.30)$ & $173(34.53)$ & $328(65.47)$ & $414(41.32)$ & $588(58.68)$ \\
\hline$\chi^{2}$ & & & 49.36 & 24.90 & & 51.09 \\
\hline P-value & & & $<0.01$ & $<0.01^{\mathrm{a}}$ & & $<0.01$ \\
\hline OR $(95 \% \mathrm{CI})$ & & & & $2.03(1.53-2.8)$ & & $1.89(1.58-2.25)$ \\
\hline
\end{tabular}

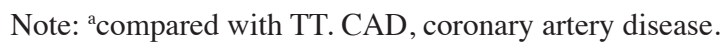

Table III. Analysis of gene polymorphism test results in the ISR and NISR groups (\%).

\begin{tabular}{|c|c|c|c|c|c|c|}
\hline \multirow[b]{2}{*}{ Group } & \multicolumn{4}{|c|}{ Genotype } & \multicolumn{2}{|c|}{ Allele } \\
\hline & $\mathrm{CC}$ & $\mathrm{CT}$ & TT & $\mathrm{CC}+\mathrm{TC}$ & $\mathrm{C}$ & $\mathrm{T}$ \\
\hline ISR group $(n=67)$ & $37(55.22)$ & $23(34.33)$ & $7(10.45)$ & $60(89.55)$ & $97(72.39)$ & $37(27.61)$ \\
\hline NISR group $(n=465)$ & $148(31.83)$ & $214(46.02)$ & $103(22.15)$ & $362(77.85)$ & $510(54.84)$ & $420(45.16)$ \\
\hline$\chi^{2}$ & & & 14.89 & 4.89 & & 14.72 \\
\hline P-value & & & 0.001 & $0.027^{\mathrm{a}}$ & & $<0.01$ \\
\hline OR $(95 \% \mathrm{CI})$ & & & & $2.44(1.08-5.50)$ & & $2.16(1.45-3.22)$ \\
\hline
\end{tabular}

Note: acompared with TT. ISR, in-stent restenosis; NISR, no in-stent restenosis.

Table IV. Connexin37 gene C1019T polymorphism distribution (\%) in males in the CAD and control groups.

\begin{tabular}{|c|c|c|c|c|c|c|}
\hline \multirow[b]{2}{*}{ Group } & \multicolumn{4}{|c|}{ Genotype } & \multicolumn{2}{|c|}{ Allele } \\
\hline & $\mathrm{CC}$ & CT & TT & $\mathrm{CC}+\mathrm{TC}$ & $\mathrm{C}$ & $\mathrm{T}$ \\
\hline CAD group $(n=432)$ & $140(32.41)$ & $204(47.22)$ & $88(20.37)$ & $344(79.63)$ & $484(56.02)$ & $380(43.98)$ \\
\hline Control group $(n=334)$ & $71(21.26)$ & $171(51.20)$ & $92(27.54)$ & $242(72.45)$ & $313(46.86)$ & $355(53.14)$ \\
\hline$\chi^{2}$ & & & 14.52 & 5.39 & & 12.67 \\
\hline P-value & & & 0.001 & $0.02^{\mathrm{a}}$ & & $<0.01$ \\
\hline OR $(95 \% \mathrm{CI})$ & & & - & $1.48(1.06-2.09)$ & & $1.45(1.18-1.77)$ \\
\hline
\end{tabular}

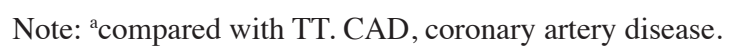

95\% CI, 1.90-5.86; $\mathrm{P}<0.01)$. In female and male CAD patients, the frequency of the connexin37 $\mathrm{C}$ allele was higher than in the healthy controls (male: $\chi^{2}=12.67, \mathrm{P}<0.01$; female: $\chi^{2}=50.20$, $\mathrm{P}<0.01$; (Tables II, IV and V).

Compared with the NISR group, the frequencies of the connexin37 $\mathrm{C}$ allele and $\mathrm{C}$ carriers (CC+TC) were significantly higher in the ISR group (frequency of $\mathrm{C}$ allele, 72.39\% vs. $54.84 \%, \mathrm{P}<0.01$; frequency of $\mathrm{C}$ carriers: $89.55 \%$ vs. $77.85 \%, \mathrm{P}=0.03$ ). Compared with TT homozygotes, the restenosis risk was significantly increased in the $\mathrm{C}$ carriers (CC+TC; OR, 2.44; 95\% CI, 1.08-5.50). Subsequent stratified analysis revealed that the frequency of the $\mathrm{C}$ allele was significantly higher in the male ISR group than in the male NISR group (78.57\% vs. 52.66\%; OR, 3.30; 95\% CI, 2.05-5.29; $\mathrm{P}<0.01)$. The restenosis risk was $\sim$ four-fold higher in the $\mathrm{C}$ carriers (CC+TC) than in the TT homozygotes (OR, 3.74 ; $95 \%$ CI, 1.32-10.64). However, in the female population, no difference was identified in the ISR risk between the $\mathrm{C}$ carriers $(\mathrm{CC}+\mathrm{TC})$ and the $\mathrm{TT}$ homozygotes $(\mathrm{P}=0.70$; Tables VI and VII). By binary logistic adjustment for age, gender, BMI, smoking, alcohol, consumption, hypertension, diabetes, hyperlipidemia, stent length and stent diameter and balloon pressure, which are risk factors of stents restenosis, the stent restenosis risk for $\mathrm{C}$ carriers was calculated to be 1.78-fold higher that of the patients carrying the $\mathrm{T}$ allele (95\%CI, 1.23-3.14; P<0.01; Tables III, VI and VII). 
Table V. Connexin37 gene C1019T polymorphism distribution (\%) in females in the CAD and control groups.

\begin{tabular}{|c|c|c|c|c|c|c|}
\hline \multirow[b]{2}{*}{ Group } & \multicolumn{4}{|c|}{ Genotype } & \multicolumn{2}{|c|}{ Allele } \\
\hline & $\mathrm{CC}$ & $\mathrm{CT}$ & TT & $\mathrm{CC}+\mathrm{TC}$ & $\mathrm{C}$ & $\mathrm{T}$ \\
\hline CAD group $(n=100)$ & $45(45.00)$ & $33(33.00)$ & $22(22.00)$ & $78(78.00)$ & $123(61.50)$ & $77(38.50)$ \\
\hline Control group $(n=167)$ & $15(8.98)$ & $71(42.51)$ & $81(48.50)$ & $86(51.50)$ & $101(30.24)$ & $233(67.76)$ \\
\hline$\chi^{2}$ & & & 48.95 & 18.54 & & 50.20 \\
\hline P-value & & & $<0.01$ & $<0.01^{\mathrm{a}}$ & & $<0.01$ \\
\hline OR $(95 \% \mathrm{CI})$ & & & & $3.34(1.90-5.86)$ & & $3.69(2.55-5.33)$ \\
\hline
\end{tabular}

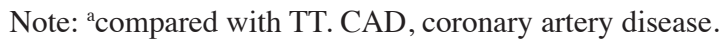

Table VI. Connexin 37 gene C1019T polymorphism distribution (\%) in males in the ISR and NISR groups.

\begin{tabular}{|c|c|c|c|c|c|c|}
\hline \multirow[b]{2}{*}{ Group } & \multicolumn{4}{|c|}{ Genotype } & \multicolumn{2}{|c|}{ Allele } \\
\hline & $\mathrm{CC}$ & $\mathrm{CT}$ & TT & $\mathrm{CC}+\mathrm{TC}$ & $\mathrm{C}$ & $\mathrm{T}$ \\
\hline ISR group $(n=56)$ & $36(64.29)$ & $16(28.57)$ & $4(7.14)$ & $52(92.86)$ & $88(78.57)$ & $24(21.43)$ \\
\hline NISR group $(n=376)$ & $104(27.66)$ & $188(50.00)$ & $84(22.34)$ & $292(77.66)$ & $396(52.66)$ & $356(47.34)$ \\
\hline$\chi^{2}$ & & & 30.44 & 6.94 & & 26.57 \\
\hline P-value & & & $<0.01$ & $0.008^{\mathrm{a}}$ & & $<0.01$ \\
\hline OR $(95 \% \mathrm{CI})$ & & & - & $3.74(1.32-10.64)$ & & $3.30(2.05-5.29)$ \\
\hline
\end{tabular}

Note: acompared with TT. ISR, in-stent restenosis; NISR, no in-stent restenosis.

Table VII. Connexin37 gene C1019T polymorphism distribution (\%) in females in the ISR and NISR groups.

\begin{tabular}{|c|c|c|c|c|c|c|}
\hline \multirow[b]{2}{*}{ Group } & \multicolumn{4}{|c|}{ Genotype } & \multicolumn{2}{|c|}{ Allele } \\
\hline & $\mathrm{CC}$ & $\mathrm{CT}$ & $\mathrm{TT}$ & $\mathrm{CC}+\mathrm{TC}$ & $\mathrm{C}$ & $\mathrm{T}$ \\
\hline ISR group $(n=11)$ & $1(9.09)$ & $7(63.64)$ & $3(27.27)$ & $8(72.73)$ & $9(40.91)$ & $13(59.09)$ \\
\hline NISR group $(n=89)$ & $44(49.44)$ & $26(29.21)$ & $19(21.35)$ & $70(78.65)$ & $114(64.04)$ & $64(35.96)$ \\
\hline$\chi^{2}$ & & & 7.21 & 0.20 & & 4.43 \\
\hline P-value & & & 0.027 & $0.655^{\mathrm{a}}$ & & 0.035 \\
\hline OR (95\% CI) & & & - & $0.72(0.18-3.00)$ & & $0.39(0.16-0.96)$ \\
\hline
\end{tabular}

Note: acompared with TT. ISR, in-stent restenosis; NISR, no in-stent restenosis.

\section{Discussion}

In the present study, the frequency of the $\mathrm{C}$ allele at base-pair 1019 of the connexin 37 gene in patients with CAD was observed to be significantly higher than that of the healthy controls, which was consistent with the study by Han et al of a northern Han population in China (16). Furthermore, the frequencies of connexin37 $\mathrm{C}$ allele and $\mathrm{C}$ carriers $(\mathrm{CC}+\mathrm{TC})$ were observed to be significantly higher in the ISR group compared with the NISR group (frequency of C allele: $72.39 \%$ vs. $54.84 \%$, $\mathrm{P}<0.01$; frequency of $\mathrm{C}$ carriers: $89.55 \%$ vs. $77.85 \%, \mathrm{P}=0.03$ ). The restenosis risk was $\sim$ three-fold higher in the carriers of the $\mathrm{C}$ allele $(\mathrm{CC}+\mathrm{TC})$ than in the $\mathrm{TT}$ homozygotes $(95 \% \mathrm{CI}$,
1.32-10.64) in the male population. The $\mathrm{C} 1019$ connexin37 SNP appears to be a risk factor for ISR in the Han population of China.

Although the pathophysiological processes of CAD and ISR are different, each starts with endothelial injury induced by hemodynamic changes (shear stress) or stent placement during PCI (20). Subsequently a cascade of events occurs, including platelet and leukocyte activation which are key to atherosclerosis and SMC proliferation which is important in restenosis. Therefore, the dysfunction of the endothelial monolayer is key to the development of CAD and ISR $(21,22)$.

The human connexin 37 gene maps to chromosome lp35.1 and encodes 333 amino acids which form the connexin 37 
protein. Connexin 37 is most highly expressed in the vascular endothelium, as well as in monocytes, macrophages and SMCs (23). Several connexin37 proteins form gap junction channels and hemichannels with unique properties, including distinct permeabilities for various signaling molecules (24). In an animal model, it was suggested that induced connexin 37 expression may be an indicator of vascular smooth muscle cells responding to hemodynamic changes (shear stress) (25). In another animal model, connexin $37^{-/} \mathrm{ApoE}^{-/-}$mice developed more aortic lesions than connexin $37^{+/+} \mathrm{ApoE}^{-/-}$control mice, indicating that connexin 37 was atheroprotective (26). Thus, the normal connexin 37 protein has a protective effect in cardiovascular diseases.

If an SNP in the connexin37 gene is a cytosine-to-thymine replacement at position 1019 (C1019T), this causes a nonconservative amino acid change in the regulatory $\mathrm{C}$-terminus of the connexin 37 protein, a proline-to-serine substitution (P319S) (27). This shift from proline to serine may lead to functional changes and different responses to regulatory mechanisms, such as phosphorylation. The creation of a new phosphorylation site may provide greater capacity for modulating the function from gap junctions made of this protein, which may modify endothelial cell function, and thus lead to different susceptibility to cardiovascular diseases, including CAD and ISR. However, further studies are required concerning the extensional mechanism by which allelic variants of connexin 37 are differentially predictive of an increased risk of CAD and ISR.

In conclusion, the present study indicates that the $\mathrm{C}$ allele in the connexin 37 gene may not only be associated with susceptibility to CAD, but also with restenosis following coronary stenting, particularly in the male population.

\section{References}

1. Serruys PW, Kutryk MJ and Ong AT: Coronary-artery stents. N Engl J Med 354: 483-495, 2006.

2. Cheng $\mathrm{G}$, Wang $\mathrm{H}$, Chen M, et al: Lack of evidence to support the association of polymorphisms within the TNFSF4 gene and coronary heart disease in a Chinese Han population. Exp Ther Med 2: 275-280, 2011

3. Yan KP, Guo Y, Xing Z, et al: Dan-Shen-Yin protects the heart against inflammation and oxidative stress induced by acute ischemic myocardial injury in rats. Exp Ther Med 3: 314-318, 2012

4. Marfella R, Sasso FC, Siniscalchi M, et al: Peri-procedural tight glycemic control during early percutaneous coronary intervention is associated with a lower rate of in-stent restenosis in patients with acute ST-elevation myocardial infarction. J Clin Endocrinol Metab 97: 2862-2871, 2012.

5. Kastrati A, Schömig A, Elezi S, et al: Interlesion dependence of the risk for restenosis in patients with coronary stent placement in multiple lesions. Circulation 97: 2396-2401, 1998.

6. Weintraub WS, Kosinski AS, Brown CL III, et al: Can restenosis after coronary angioplasty be predicted from clinical variables? J Am Coll Cardiol 21: 6-14, 1993.

7. Saez JC, Berthoud VM, Branes MC, et al: Plasma membrane channels formed by connexins: their regulation and functions. Physiol Rev 83: 1359-1400, 2003.
8. Fang JS, Angelov SN, Simon AM and Burt JM: Cx37 deletion enhances vascular growth and facilitates ischemic limb recovery. Am J Physiol Heart Circ Physiol 301: H1872-H1881, 2011.

9. Kanady JD, Dellinger MT, Munger SJ, Witte MH and Simon AM: Connexin37 and Connexin43 deficiencies in mice disrupt lymphatic valve development and result in lymphatic disorders including lymphedema and chylothorax. Dev Biol 354: 253-266, 2011.

10. Morel S and Kwak BR: Roles of connexins in atherosclerosis and ischemia-reperfusion injury. Curr Pharm Biotechnol 13: 17-26, 2012.

11. Yeh HI, Chang HM, Lu WW, et al: Age-related alteration of gap junction distribution and connexin expression in rat aortic endothelium. J Histochem Cytochem 48: 1377-1389, 2000.

12. Pfenniger A, Wong C, Sutter E, et al: Shear stress modulates the expression of the atheroprotective protein $\mathrm{Cx} 37$ in endothelial cells. J Mol Cell Cardiol 53: 299-309, 2012.

13. Fang JS, Angelov SN, Simon AM and Burt JM: Cx40 is required for, and cx37 limits, postischemic hindlimb perfusion, survival and recovery. J Vasc Res 49: 2-12, 2012.

14. Boerma M, Forsberg L, Van Zeij L, et al: A genetic polymorphismin connexin 37 as a prognostic marker for atherosclerotic plaque development. J Intern Med 246: 211-218, 1999.

15. Yeh HL, Chou Y, Liu HF, et al: Connexin37 gene polymorphism and coronary artery disease in Taiwan. Int J Cardiol 81: 251-255, 2001.

16. Han YL, Xi SY, Zhang XL, et al: Association of C1019T polymorphism in the Connexin 37 gene and coronary artery disease in Chinese Han population. Zhonghua Yi Xue Za Zhi 87:100-104, 2007 (In Chinese).

17. Wong CW, Christen T, Pfenniger A, et al: Do allelic variants of the connexin37 1019 gene polymorphism differentially predict for coronary artery disease and myocardial infarction? Atherosclorosis 191: 355-361, 2007.

18. Yamada Y, Izawa H, Ichiwara S, et al: Prediction of the risk of myocardial infarction from polymorphisms in candidate genes. N Engl J Med 347: 1916-1923, 2002.

19. Listi F, Candore G, Lio D, et al: Association between C1019T polymorphism of connexin 37 and acute myocardial infarction: a study in patients from Sicily. Int J Cardiol 102: 269-271, 2005.

20. Chan JM, Rhee JW, Drum CL, et al: In vivo prevention of arterial restenosis with paclitaxel-encapsulated targeted lipid-polymeric nanoparticles. Proc Natl Acad Sci U S A 108: 19347-19352, 2011.

21. Egan CG, Caporali F, Huqi AF, et al: Reduced levels of putative endothelial progenitor and $\mathrm{CXCR} 4^{+}$cells in coronary artery disease: kinetics following percutaneous coronary intervention and association with clinical characteristics. Thromb Haemost 101: 1138-1146, 2009.

22. Stiefel P, Moreno-Luna R, Vallejo-Vaz AJ, et al: Which parameter is better to define endothelial dysfunction in a test of postocclusive hyperemia measured by laser-Doppler flowmetry? Coron Artery Dis 23: 57-61, 2012.

23. Leu HB, Chung CM, Chuang SY, et al: Genetic variants of connexin 37 are associated with carotid intima-medial thickness and future onset of ischemic stroke. Atherosclerosis 214: 101-106, 2011.

24. Puljung MC, Berthoud VM, Beyer EC and Hanck DA: Polyvalent cations constitute the voltage gating particle in human connexin37 hemichannels. J Gen Physiol 124: 587-603, 2004.

25. Cai WJ, Koltai S, Kocsis E, et al: Connexin37, not Cx40 and $\mathrm{Cx} 43$, is induced in vascular smooth muscle cells during coronary arteriogenesis. J Mol Cell Cardiol 33: 957-967, 2001.

26. Wong CW, Christen T, Roth I, et al: Connexin 37 protects against atherosclerosis by regulating monocyte adhesion. Nat Med 12: 950-954, 2006.

27. Collings A, Raitakari OT, Juonala M, et al: The influence of smoking and homocysteine on subclinical atherosclerosis is modified by the connexin37 C1019T polymorphism - The Cardiovascular Risk in Young Finns Study. Clin Chem Lab Med 46: 1102-1108, 2008. 